\title{
Tumor-secreted SDF-1 promotes glioma invasiveness and TAM tropism toward hypoxia in a murine astrocytoma model
}

\author{
Shu-Chi Wang ${ }^{1}$, Ji-Hong Hong ${ }^{2}$, Chuen Hsueh ${ }^{3}$ and Chi-Shiun Chiang ${ }^{1}$
}

\begin{abstract}
A distinguishing feature of high-grade gliomas is the infiltration of neoplastic cells into adjacent brain tissues that mark most of these tumors surgically incurable. To study the factors associated with tumor invasion, we established a new murine brain tumor model, ALTS1C1 derived from SV40 large T antigen-transfected astrocytes. This new brain tumor model recapitulates several histopathological features of human high-grade glioma including increased cellularity, prominent cellular pleomorphism, geographic necrosis, active mitosis, and extensive invasion of tumor cells into adjacent brain tissues. More importantly, ALTS1C1 expressed a relatively high level of stromal-derived factor-1 (SDF-1/CXCL12) in vitro and in vivo and higher microvascular density (MVD) in vivo. To define the roles of SDF-1 in this tumor model, the expression of SDF-1 in ALTS1C1 cells was inhibited by specific siRNA. SDF-knockdown ALTS1C1 (SDF ${ }^{\mathrm{kd}}$ ) cells took longer than parental ALTS1C1 cells to form tumors and in contrast to the wild-type tumors they had well-defined regular borders and lacked infiltration tracts. The SDF ${ }^{\mathrm{kd}}$ tumors were also associated with a lower MVD and more hypoxic areas. In contrast to parental tumors, the density of F4/80-positive tumor-associated macrophages (TAMs) in SDF ${ }^{\mathrm{kd}}$ tumor was higher in non-hypoxic than in hypoxic regions. SDF-1 production by tumor cells therefore seems critical for the aggregation of TAMs into areas of hypoxia and tumor invasiveness. This study not only provides new insight into the role of SDF-1 in brain tumor invasion and the relationship between TAMs and hypoxia, but also provides a new preclinical brain tumor model for designing new treatment options for invasive cases.
\end{abstract}

Laboratory Investigation (2012) 92, 151-162; doi:10.1038/labinvest.2011.128; published online 5 September 2011

KEYWORDS: glioma; invasion; SDF-1; tumor-associated macrophages

Gliomas, in particular malignant astrocytomas, give a poor prognosis and are incurable in most patients. Glioblastoma (GBM; WHO grade IV) and astrocytoma represent $77.5 \%$ of all cases of glioma. GBMs are the most aggressive form and are associated with extremely poor survival rates: $<10 \%$ of patients with GBMs survive $>2$ years. ${ }^{1}$ GBMs may develop as primary GBMs or through malignant progression from low-grade astrocytoma (grade II) or anaplastic astrocytoma (grade III) as secondary GBMs. ${ }^{2}$ Radiation therapy (RT) is one of the front-line treatments for malignant gliomas being the most effective treatment after surgery. We have previously shown that RT disturbs the tumor microenvironment, including the vascular network and the extent of hypoxia, which could cause resistance to future therapy. ${ }^{3}$ Since surgery, RT, chemotherapy, or a combination of multiple modalities cannot achieve satisfactory treatment outcomes, the development of new treatment strategies to improve patient outcome is necessary.

A distinguishing feature of high-grade gliomas is infiltration into surrounding normal brain tissue that makes most of these tumors surgically incurable. Preclinical glioma models that can recapitulate this feature are essential for better understanding of the behavior of malignant brain tumors and the design of new therapeutic interventions. Many preclinical glioma models have been reported that are derived by gene targeting in transgenic mice, ${ }^{4}$ by carcinogen induction, ${ }^{5}$ and by viral infection. ${ }^{6}$ Each has drawbacks and restrictions. For example, 4C8 cells from B6D2F1 transgenic mice develop a pattern of necrosis and express glial fibrillary acidic protein (GFAP), but are not very aggressive. ${ }^{7}$ The C57BL/6 syngeneic

\footnotetext{
${ }^{1}$ Department of Biomedical Engineering and Environmental Sciences, National Tsing-Hua University, Hsinchu, Taiwan; ${ }^{2}$ Department of Radiation Oncology, Chang-Gung Memorial Hospital, Taoyuan, Taiwan and ${ }^{3}$ Department of Pathology, Chang-Gung Memorial Hospital, Taoyuan, Taiwan

Correspondence: Dr C-S Chiang, PhD, Department of Biomedical Engineering and Environmental Sciences, National Tsing-Hua University, 101, Section 2, Kuang-Fu Road, Hsinchu 30013, Taiwan.

E-mail: cschiang@mx.nthu.edu.tw

Received 21 March 2011; revised 29 June 2011; accepted 3 July 2011
} 
203 glioma was induced by 20 -methylcholanthrene, ${ }^{5}$ but it is unclear what genetic alterations are associated with it. The C57BL/6 syngeneic GL261 tumor that is commonly used was originally established by intracranial injection of 3-methylcholantrene (MCA) and maintained by serial transplantations. GL261 cells are easily adapted to in vitro growth and have aggressive growth characteristics when grown intracranially. However, unlike human GBM cell lines (such as U87MG, U-373MG, and T98G), GL261 tumors are radiosensitive. ${ }^{8}$ Another model that could simulate human high-grade glioma with respect to their infiltrative and radioresistant nature would therefore be useful for studying the behavior of malignant brain tumors and designing new therapeutic interventions.

The tumor microenvironment has a critical role in tumor growth and metastasis, as do tumor-associated macrophages (TAMs). TAMs represent the largest population of infiltrating inflammatory cells in malignant gliomas. The number of CD68-positive TAMs is higher in GBMs than that in grade II or III gliomas and a positively correlates with vascular density. ${ }^{9}$ Reports have shown that TAMs can promote the proliferation of glioma cells, enhance their invasion at tumor margins, and stimulate angiogenesis in perivascular areas. ${ }^{10}$ The multiple proangiogenic factors produced by TAMs may explain reported correlations between increased TAM numbers and high vascular grades in several types of tumors. ${ }^{9}$

A number of tumor-derived chemoattractants, including chemokines and chemokine receptor families, ${ }^{11,12}$ are thought to ensure TAM recruitment. Among the factors that can contribute to the invasive phenotype of glioma cells, stromal-derived factor-1 (SDF-1) has gained increased attention recently. SDF-1 through its receptor, CXCR4, has been shown to be a major player in tumor metastasis and growth in several human malignancies. ${ }^{13-15}$ The SDF-1/ CXCR4 axis brings about these effects by recruiting bone marrow derived cells to neovascular niches to promote angiogenesis, ${ }^{16}$ as well as stimulating the proliferation and survival of tumor cells in a paracrine manner. ${ }^{17} \mathrm{~A}$ major stimulus for SDF-1 production is hypoxia through the generation of HIF-1. The SDF-1 can in turn enhance the survival of bone marrow-derived mesenchymal stem cells under hypoxic conditions through activation of PI3K/Akt and ERK1/2 pathways. ${ }^{18}$

In this study, we introduce a new preclinical glioma model, ALTS1C1, derived from primary astrocytes transformed by SV40 large T antigen (LTA), followed by serial subcutaneous and intracranial passages. In addition to recapturing numerous neuropathological features of human high-grade brain tumors, the ALTS1C1 displays several distinct tumor microenvironments associated with the primary tumor core, the infiltration fronts, and the tumor cell islands. We found this tumor expresses a relatively high level of SDF-1 in vitro and in vivo and inhibition of SDF-1 production reduced tumor invasiveness and TAM tropism toward hypoxia. These features may help to better understand the roles of tumor microenvironments in tumor invasion and make ALTS1C1 a good choice as a preclinical brain tumor model for designing new treatment options for invasive cases.

\section{MATERIALS AND METHODS Primary Astrocyte Culture and SV40 T Antigen Gene Transfection}

Brains from 2-day-old C57BL/6 mice were used to establish the primary astrocyte cultures. The culture processing has been described previously. ${ }^{19}$ Briefly, brain tissues were homogenized and passed successively through $75 \mu \mathrm{m}$ and $40 \mu \mathrm{m}$ nylon strainers (BD Bioscience, San Jose, CA, USA). Brain cells were seeded into $10 \mathrm{~cm}$ dishes to which was added the RPMI- 1640 medium containing $10 \%$ fetal calf serum and penicillin/streptomycin antibiotics. The dishes were left untouched for 3 days for cell attachment and thereafter the medium was changed every 3 days. After 7-16 days in culture, the oligodendrocyte and microglia cells appearing on the top of astrocytes were separated by mechanical shaking technique. The cells that remained attached on the dishes contained $>95 \%$ astrocytes as recognized by mouse monoclonal anti-mouse GFAP antibody (Sigma, St Louis, MO, USA). The pMT10D plasmid ( $5 \mu \mathrm{g}$ ) bearing origin-defective SV40 T antigen gene, ${ }^{20}$ purchased from the Japan Health Sciences Foundation (Reference No.: FG-2004-005), were transfected into $1 \times 10^{6}$ astrocytes using SuperFect Transfection Reagent (Qiagene, Germantown, MD, USA) for $48 \mathrm{~h}$. Cells were incubated under normal culture conditions for $>3$ months. The cells that survived $>3$ months were harvested and serially passed in vitro. The established cell line was named 'ALT'.

\section{In Vitro Growth Curve}

Ten thousand $\left(1 \times 10^{4}\right)$ cells were plated on $100 \mathrm{~mm}$ dishes. The viable cell number was counted in a hemacytometer every $12 \mathrm{~h}$ after trypsinization and trypan blue staining.

\section{Immunoblotting}

Western blot analysis was performed with $20 \mu \mathrm{g}$ protein extracts separated by $10 \%$ polyacrylamide gel and probed by anti-mouse LTA monoclonal antibody (1:1000; Clone PAb101; BD Pharmingen, San Diego, CA, USA), anti-mouse GFAP monoclonal antibody (1:1000; Clone G-A-5; Sigma) or an anti-actin antibody (1:5000; Clone ACTN05; Thermo, Fremont, CA, USA) as loading control.

\section{Real-Time Quantitative PCR and RT-PCR}

Total RNA was extracted from cells with TRIzol (Invitrogen, Carlsbad, CA, USA) according to the manufacturer's manual. In all, $2 \mu \mathrm{g}$ of total RNA was reverse transcribed using Super Script III RNase $\mathrm{H}$ reverse transcriptase (Invitrogen) and random hexamer primers (Invitrogen) at $25^{\circ} \mathrm{C}$ for $10 \mathrm{~min}$ and $42{ }^{\circ} \mathrm{C}$ for $1 \mathrm{~h}$ to synthesize cDNA.

Quantitative PCR (Q-PCR) was performed in a TaqMan 5700 sequence detection system (Applied Biosystems, Foster 
City, CA, USA). The gene primers were designed by the Primer Express 3.0 software. Power SYBR Green PCR reactions were performed in triplicate for each sample and analyzed using the ABI Prism 7900HT sequence detection system. Data were normalized to actin levels and 7300 system software was used to analyze the amplified transcripts according to the threshold cycle $(\mathrm{Ct})$ method. The difference $(\Delta \mathrm{Ct})$ between the $\mathrm{Ct}$ of the gene transcript and the endogenous control actin determined the gene expression. The fold-change of each target mRNA was calculated by the formula $2^{-\Delta \Delta \mathrm{Ct}}$.

For RT-PCR, total RNA was extracted from cells with TRIzol (Invitrogen) as per the manufacturer's directions. Two micrograms of total RNA was reverse transcribed using Super Script III RNase $\mathrm{H}$ reverse transcriptase (Invitrogen) and random hexamer primers (Invitrogen) at $25^{\circ} \mathrm{C}$ for $10 \mathrm{~min}$ and $42{ }^{\circ} \mathrm{C}$ for $1 \mathrm{~h}$ to synthesize cDNA. In all, $2 \mu \mathrm{l}$ of the reverse transcription product was used as a template for PCR amplification. PCR was performed using Taq polymerase (Invitrogen) and $150 \mathrm{nmol} / \mathrm{l}$ of primers. The PCR conditions consisted of $3 \mathrm{~min}$ of an initial denaturation step $\left(95^{\circ} \mathrm{C}\right.$ followed by 30 cycles of denaturation $\left(95^{\circ} \mathrm{C}, 30 \mathrm{~s}\right)$, annealing $\left(57^{\circ} \mathrm{C}, 30 \mathrm{~s}\right)$, and extension $\left(72^{\circ} \mathrm{C}, 30 \mathrm{~s}\right)$ followed by a final elongation step of $10 \mathrm{~min}$ at $72{ }^{\circ} \mathrm{C}$. In all, $10 \mu \mathrm{l}$ of PCR product was analyzed on $2 \%$ agarose gels stained with ethidium bromide. Quantitation of bands was performed using ImageJ software (NIH, Bethesda, MD, USA).

\section{Orthotopic Intracranial Tumor Implantation}

To implant ALTS1C1 or GL261 cells (kindly provided by Professor Newcomb, New York University), $2 \mu$ l of $1 \times 10^{5}$ cells was inoculated intracranially to 6 - to 8 -week-old C57BL/6 mice as described. ${ }^{21}$ (see Supplemental Methods). Before the kill, the animals were anesthetized and then perfused transcardially with PBS followed by $4 \%$ paraformaldehyde. Tumor hypoxia was studied by i.v. injection of $4 \mathrm{mg}$ pimonidazole hydrochloride (Hypoxyprobe $^{\mathrm{TM}}-1 \mathrm{Kit}$, Chemicon, Billerica, MA, USA) in $0.1 \mathrm{ml}$ solution $1 \mathrm{~h}$ before tumor harvest. Brains were removed and placed in cold $4 \%$ paraformaldehyde overnight then processing and embedding in paraffin or OCT. The hematoxylin and eosin (H\&E)stained maximal crosssections were used as a measurement of tumor diameter and the examination of overall tumor histopathology. During the experiments, all mice were cared for accordance with the approved guide by the Institutional Animal Care and Use Committee (IACUC), National Tsing Hua University, Taiwan (approved number: IACUC:09705).

\section{Immunohistochemistry}

Tissues embedded in OCT were used for immunohistochemistry (IHC) staining. Frozen tumors were sectioned $(8 \mu \mathrm{m})$, mounted onto slides, and maintained at $-20^{\circ} \mathrm{C}$. To perform IHC staining, cells were fixed with methanol and permeabilized in $0.01 \%$ Tween-20/0.1\% Triton X-100 in PBS. Slides were blocked with blocking buffer (4\% FBS and $1 \%$ normal serum of secondary antibody host) for $30 \mathrm{~min}$ at room temperature. The following antibodies were used: mouse anti-mouse GFAP (Clone G-A-5; Sigma), rat anti-mouse CD31 (Clone MEC13.3; BD Pharmingen), rat anti-mouse F4/80 (Clone CI:A3-1; AbD Serotec, Oxford, UK), rabbit anti-mouse CD68 (Clone FA-11; AbD Serotec), rabbit anti-mouse SDF-1 (Clone 247506; R\&D systems, Minneapolis, MN, USA), rat anti-mouse vascular endothelial growth factor receptor 2 (VEGFR-2) (Clone AVAS 12a1; BD Pharmingen), and mouse anti-pimonidazole (PIMO) (Chemicon). Slides were washed and incubated with antidifferent host of secondary antibodies conjugated with Alexa Fluor 488, Alexa Fluor 594 (Invitrogen) or conjugated with biotinylated secondary antibody (BD Pharmingen) for $2 \mathrm{~h}$. The sections were washed and mounted with DAPI $(5 \mu \mathrm{g} / \mathrm{ml}$; Invitrogen) to visualize nuclei. Images were viewed and captured by an AxioCam MRC- 5 camera on an Axiovert 40 fluorescence microscope (Carl Zeiss, Göttingen, Germany) or Laser Scanning Confocal microscope (FluoView 1000, Olympus, Japan) and processed using Image-pro plus 6.0 software.

\section{Lentiviral Infection}

SDF-1 shRNA lentiviral viral particles (sc-39368-v) were purchased from Santa Cruz Biotechnology (Santa Cruz, CA, USA) and infection was performed according to the manufacturer's manual. Briefly, the ALTS1C1 cells were grown to $\sim 50 \%$ confluency in a 12 -well plate on the day of infection. The medium was replaced with fresh medium containing $5 \mu \mathrm{g} / \mathrm{ml}$ polybrene and $10^{5}$ infectious units (IFU) of SDF-1 shRNA lentiviral particles (sc-39368-v). After $24 \mathrm{~h}$ of incubation, the medium was replaced with fresh $5 \mu \mathrm{g} / \mathrm{ml}$ puromycin containing medium every 3-4 days until resistant colonies were identified.

\section{Apoptosis Assay}

Following co-culture for $72 \mathrm{~h}$, cells were harvested and analyzed using Annexin V-FITC Apoptosis Detection Kit. Samples were analyzed using a FACSCaliber flow cytometer. Cytometric analysis was conducted using FACSDiva software, version 6.1.3 (BD Bioscience).

\section{Migration Assay}

The migration assay was performed using Biocoat invasion chambers (354578, BD Bioscience) with $8 \mu \mathrm{m}$ pore size polycarbonate filter inserts for 24 -well plates. In all, $5 \times 10^{4}$ RAW264.7 cells (BCRC No. 60001) were seeded onto the upper chamber in $300 \mu \mathrm{l}$ culture medium containing $1 \%$ of FBS and placed into wells containing $700 \mu$ l of various condition mediums with final volume in the presence of $5 \%$ of FBS. The migration chambers were incubated for $6 \mathrm{~h}$ in normal or hypoxic conditions (NBO-OC101, NexBioxy, HsinChu, Taiwan). After incubation, the inserts were fixed and stained and the number of migrating cells was counted as described. ${ }^{22}$ Each assay was performed in duplicate and 
repeated twice. The data from at least three independent experiments were pooled for statistical analysis.

\section{Statistics}

Statistical analyses were performed using the two-tailed Student's $t$-test or one-way ANOVA to determine statistical significance. $P$-values (exact significance) of $<0.05$ were considered statistically significant. All calculations were performed using GraphPad Prism 4.

\section{RESULTS}

\section{Generation and Characterization of a Murine Astrocytoma Cell Line, ALTS1C1}

The pMTI0D plasmid ${ }^{20}$ was used to transfect primary murine astrocytes. After 60 days in vitro culture, the un-transfected astrocytes perished and the SV40-transfected cells, named ALT, gained proliferative ability (Figure 1a). The population doubling time of ALT cells was $\sim 18 \pm 2.8 \mathrm{~h}$. The ALT cell line cannot form tumors in syngeneic C57BL/6J mice, but a cell line that would was derived by subcutaneously inoculating $1 \times 10^{6}$ ALT cells into SCID mice. One million tumor cells were isolated from the tumors that formed and subcutaneously injected into C57BL/6J mice.
When tumors reached $6 \mathrm{~mm}$ in diameter 18 days after injection, cells were isolated and the line named 'ALTS1C1'. When $1 \times 10^{5}$ cells of ALTS1C1 were inoculated intracranially, most mice died within 28 days with a median survival time $\left(\mathrm{SF}_{50}\right)$ of 24 days (Figure 1b). GL261 tumorbearing mice had slightly shorter survival times $\left(\mathrm{SF}_{50}=21\right.$ days), despite the ALTS1C1 cells growth rate being faster than GL261 in culture (Figure 1a) and in the brain (the insert in Figure $1 \mathrm{~b}$ ). Both the tumorigenic assay and ${ }^{18}$ F-FDG PET imaging demonstrate that the ALTS1C1 cell line rapidly formed tumors in both the ectopic and intracranial sites (Supplementary Figure S1).

To characterize this newly established cell line, we first examined the expression of LTA using the western blot assay. LTA was detected in ALT cells, but not in ALTS1C1 cells or parental astrocytes (Figure 1c). This indicates that the expression of LTA was either lost or suppressed as the result of immunoediting during the process of in vivo passage, which may be similar to the loss of T antigen by TRAMP cell lines. ${ }^{23}$ Astrocytes, ALT, and ALTS1C1 all expressed GFAP, a tissue-specific marker for astrocyte lineage. The progression of astrocytoma grade has been reported as associated with a set of genetic alterations. ${ }^{24}$ In ALTS1C1, several
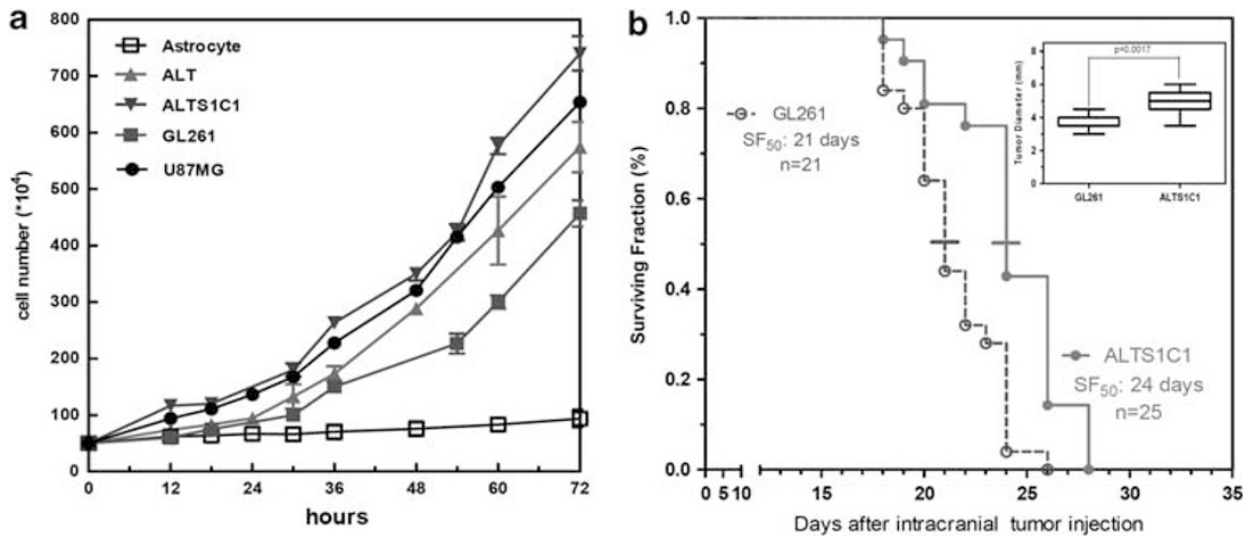

c

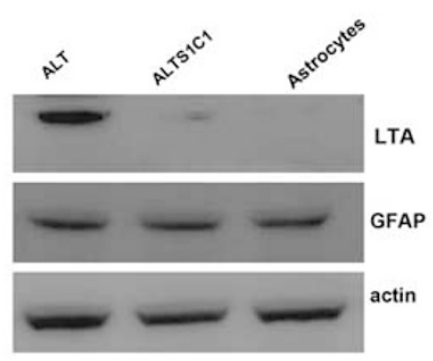

d

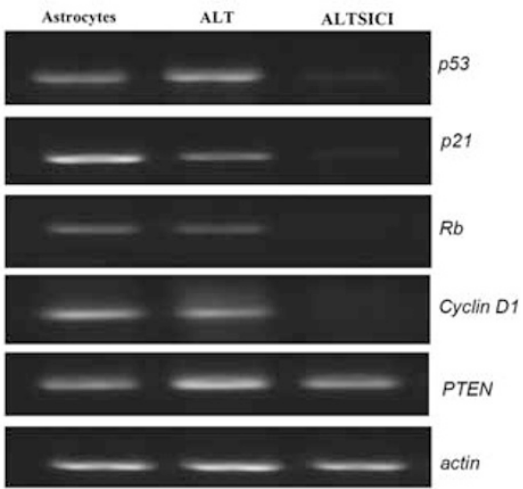

Figure 1 Characterization of ALTS1C1 tumors. (a) In vitro growth curve of primary astrocytes, ALT, ALTS1C1, murine GL261, and human U87MG cells. (b) Kaplan-Meier survival curves of ALTS1C1 $(n=25)$ and GL261 $(n=21)$ glioma-bearing mice. The inner figure is the mean diameter of GL261 and ALTS1C1 tumors in the brain measured at the maximum cross section in H\&E-stained tissues. (c) Western blot analysis for the expression of ALT and GFAP proteins by primary astrocytes, ALT and ALTS1C1 cells. (d) RT-PCR analysis for the expression of $p 53, p 21, R b$, PTEN, and actin mRNA in primary astrocytes, ALT, and ALTS1C1 cells. 
carcinogenesis-associated genes such as $p 53, p 21, R b$, and cyclin were in fact down-regulated (Figure 1d), but DNA sequencing found one point mutation in exon 6 of the $p 53$ hotspot gene region, in which the wild-type CAC code (His) is mutated to CTC code (Leu) (data not shown). The PTEN gene appears to be intact, indicating that the ALTS1C1 tumor can be classified as an anaplastic astrocytoma. ${ }^{25}$

\section{The Histopathology and Tumor Microenvironments of ALTS1C1 Tumors}

Mice with intracranial ALTS1C1 tumors developed an apparent neurological disorder that causes them to die within 2 days. Neuropathological examination of their brains showed ALTS1C1 tumors of large volume with specific invasion patterns along blood vessels. The ALTS1C1 tumors contained many atypical multinucleated cells (Figure 2a) and displayed an invasive infiltrating pattern (Figure $2 b$ ) in the tumor margin edge similar to those reported in other malignant brain tumors. Although the tissues (Figure 2b) from sick mice displayed pattern of necrosis $(13.2 \pm 3.9 \%)$, they were not so extensive as described in some grade IV GBM. The ALTS1C1 tumors had a relatively high proliferation index as judged by the staining of Ki67 nuclear protein (Supplementary Figure S2a) and most Ki67-positive cells were vWf negative (Supplementary Figure S2b). A relatively low number of Ki67 and vWf double-positive cells were occasionally found in the vessels (the arrow in Supplementary Figure S2b and the confocal imaging of S2c). This indicated that ALTS1C1 tumors do not have abnormal vascular hyperplasia as reported for grade IV GBM. However, the presence of necrotic zones surrounded by pseudopalisading cells, marked nuclear pelomorphism and active mitosis (Supplementary Figure S2d), indicating that ALTS1C1 tumors represent a GBM multiforme (grade IV).

Paraffin and frozen IHC stains confirmed that the astrocyte-specific marker, GFAP, was expressed by the tumors (Supplementary Figure S3a) and that CD44, an early marker of astrocyte differentiation, was also present but not the IDH1 protein, which is frequently mutated in high-grade gliomas $^{26}$ (Supplementary Figure S3b). The ALTS1C1 tumor cells infiltrating into the adjacent brain tissues were in the form of single or strings of cells and were associated with a high level of CD31 (Figure 2c). These infiltration islands expressed higher levels of VEGFR-2 and SDF-1 than the primary tumor core (Figures $2 \mathrm{~d}$ and e) and had a higher microvascular density (MVD) (Figure 2f). Q-PCR confirmed expression of SDF-1, hypoxia-inducible factors (HIF-1 $\alpha$ ), matrix metallopeptidase (MMP-2), VEGF, and transforming growth factor- $\beta$ (TGF- $\beta$ ) in ALTS1C1 cells as compared with prenatal astrocytes or GL261 (Supplementary Figure S3d).

\section{The Distribution of TAMs on ALTS1C1 Growing in the Brain}

Studies have shown that TAMs have significant roles in tumor growth and response to therapy. ${ }^{27}$ Using flow cytometry, we discovered that the number of $\mathrm{CD} 11 \mathrm{~b}+$ and $\mathrm{CD} 45+$ macrophages, which include $\mathrm{CD} 45^{\mathrm{mid}} / \mathrm{CD} 11 \mathrm{~b}^{\mathrm{hi}}$ microglia and $\mathrm{CD} 45^{\text {hi }} / \mathrm{CD} 11 \mathrm{~b}^{\mathrm{hi}}$ macrophages, was significantly increased in ALTS1C1 tumor-bearing brains compared with the PBS-injected controls (Supplementary Figure S4). This indicates that brain resident microglia $\left(\mathrm{CD} 45^{\mathrm{mid}} / \mathrm{CD} 11 \mathrm{~b}^{\mathrm{hi}}\right.$ population) were activated and peripheral macrophages $\left(\mathrm{CD} 45^{\mathrm{hi}} / \mathrm{CD} 11 \mathrm{~b}^{\mathrm{hi}}\right.$ population) were recruited into tumors. The TAMs in brain tumors generally include these two populations, which are difficult to distinguish by conventional IHC. To further explore the interaction between brain tumor cells and surrounding brain tissues, the distribution of TAMs in the brain tumor was examined by confocal imaging using the general myeloid differentiation markers CD68 and F4/80. We found different expression levels of these two markers in the tumor core $v s$ tumor margin. TAMs in the primary tumor core expressed both markers almost equally and were double stained (Figure 3a), but in the tumor margin and the infiltration islands (Figure $3 \mathrm{~b}$ ) there were higher levels of F4/80 than CD68 (Figure 3c) and some F4/ $80+/$ CD68 - cells (white arrow in Figure 3d).

\section{The Influence of SDF-1 on the Tumor Microenvironments of ALTS1C1 Tumors}

The aforementioned results indicate that the invading tumor phalanx has a distinct microenvironment from that of the primary tumor core. The invasive regions had a higher MVD that was associated with higher levels of F4/80-positive TAMs, VEGFR-1, and SDF-1 expression (Figure 2). Q-PCR data also showed that ALTS1C1 cells expressed the SDF-1associated genes HIF- $1 \alpha$, TGF- $\beta$, and MMP-2 (Supplementary Figure S3d).

Several reports have shown that SDF-1 production contributes significantly to tumor blood vessel formation. ${ }^{28-30} \mathrm{To}$ further explore the roles of SDF-1, its production by ALTS1C1 cells was suppressed by transfection with lentivirus particles carrying SDF-1 specific siRNA. SDF-knockdown ALTS1C1 $\left(\mathrm{SDF}^{\mathrm{kd}}\right)$ cells expressed relatively low levels of SDF-1 mRNA and protein as assessed by RT-PCR and western blot (Supplementary Figure S5a). Silencing efficiency was also demonstrated by flow cytometry and ELISA assay in vitro (Supplementary Figures S5b and c) and in vivo by SDF-1 IHC staining (Supplementary Figure S5d). SDF-1 detected by IHC of $\mathrm{SDF}^{\mathrm{kd}}$ tumors in vivo was largely associated with hypoxic PIMO-positive areas and co-localized with F4/80-positive TAMs (Supplementary Figure S6) although low levels could be seen in some F4/80-negative cells, which could be endothelial or tumor cells producing residual levels (Supplementary Figure S5c). SDF ${ }^{\mathrm{kd}}$ tumors had a significant decrease in MVD, an increase in hypoxia, as shown by PIMO staining (Figure 4a), and a very clear border with the normal tissue, lacking infiltration tracts seen in ALTS1C1 tumors (Figure 4a). When whole brain serial sections were stained with DAPI, ALTS1C1 tumors had $13.8 \pm 6.2$ tumor islands per section infiltrating non-tumor brain regions (inner image in 

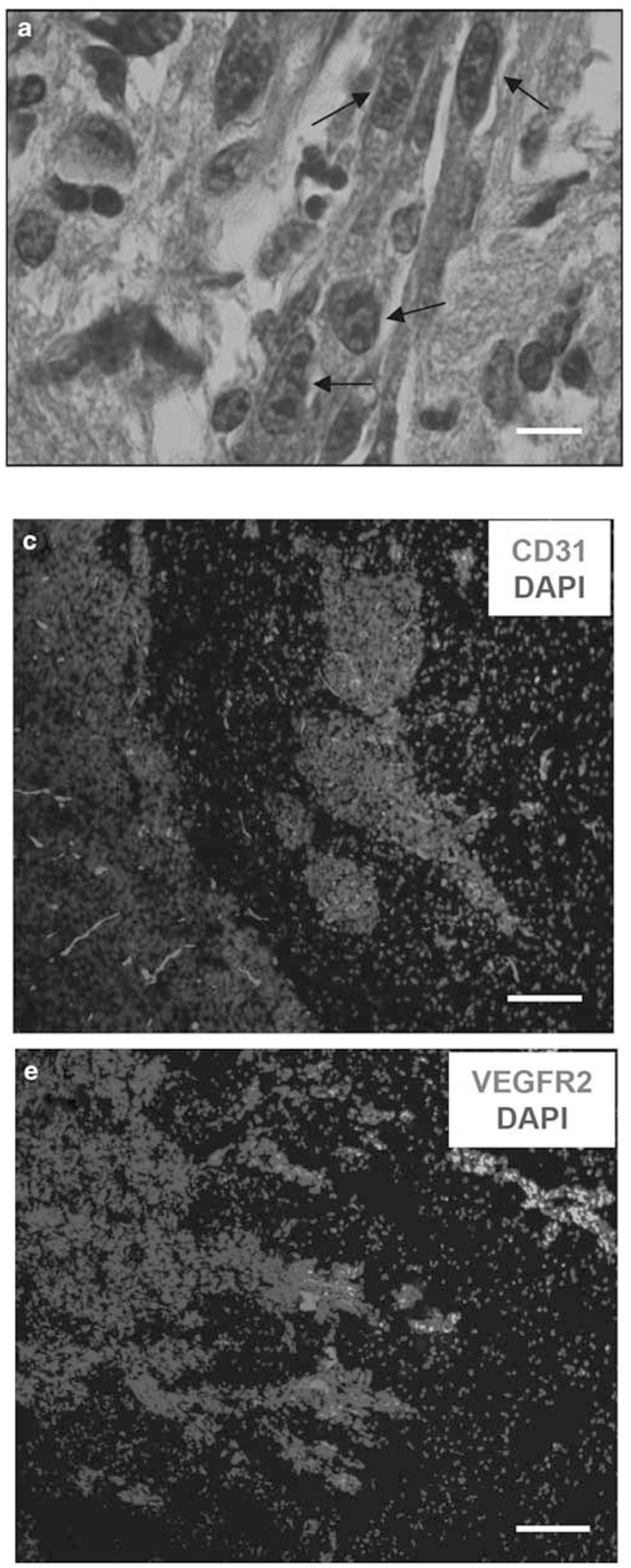
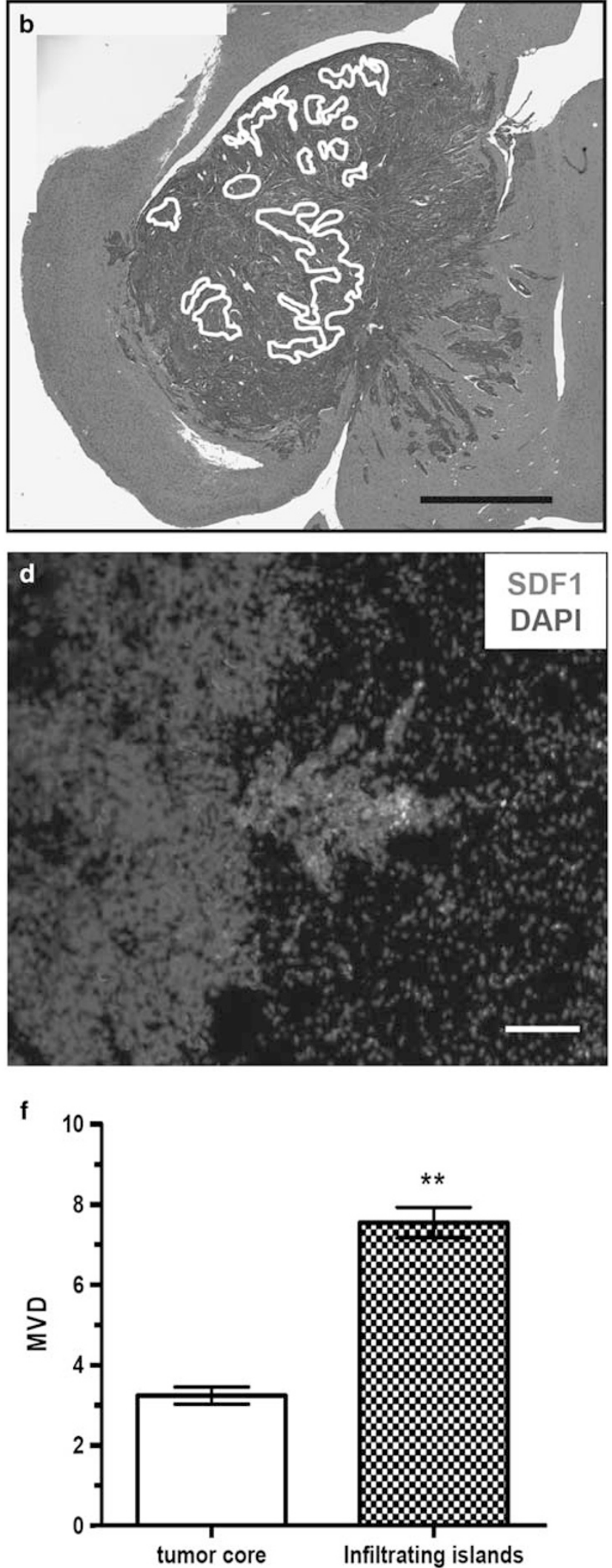

Figure 2 Histopathology of the murine ALTS1C1 brain tumors. (a) H\&E stain of the coronal sections of ALTS1C1 tumor-bearing brain. Black arrows indicated the atypical multinucleic cells. Scale $b a r=20 \mu \mathrm{m}$. (b) Low field imaging shows the tumor invasion into the adjacent brain tissues. Necrotic regions (white line) were selected and quantified by ImagePro software. Scale bar $=1 \mathrm{~mm}$. IHC staining of the frozen sections of ALTS1C1 brain tumor by (c) CD31, (d) SDF-1, or (e) VEGFR-2

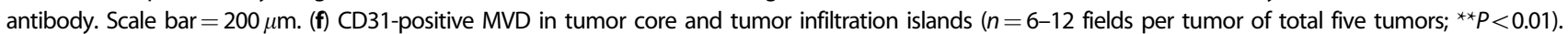



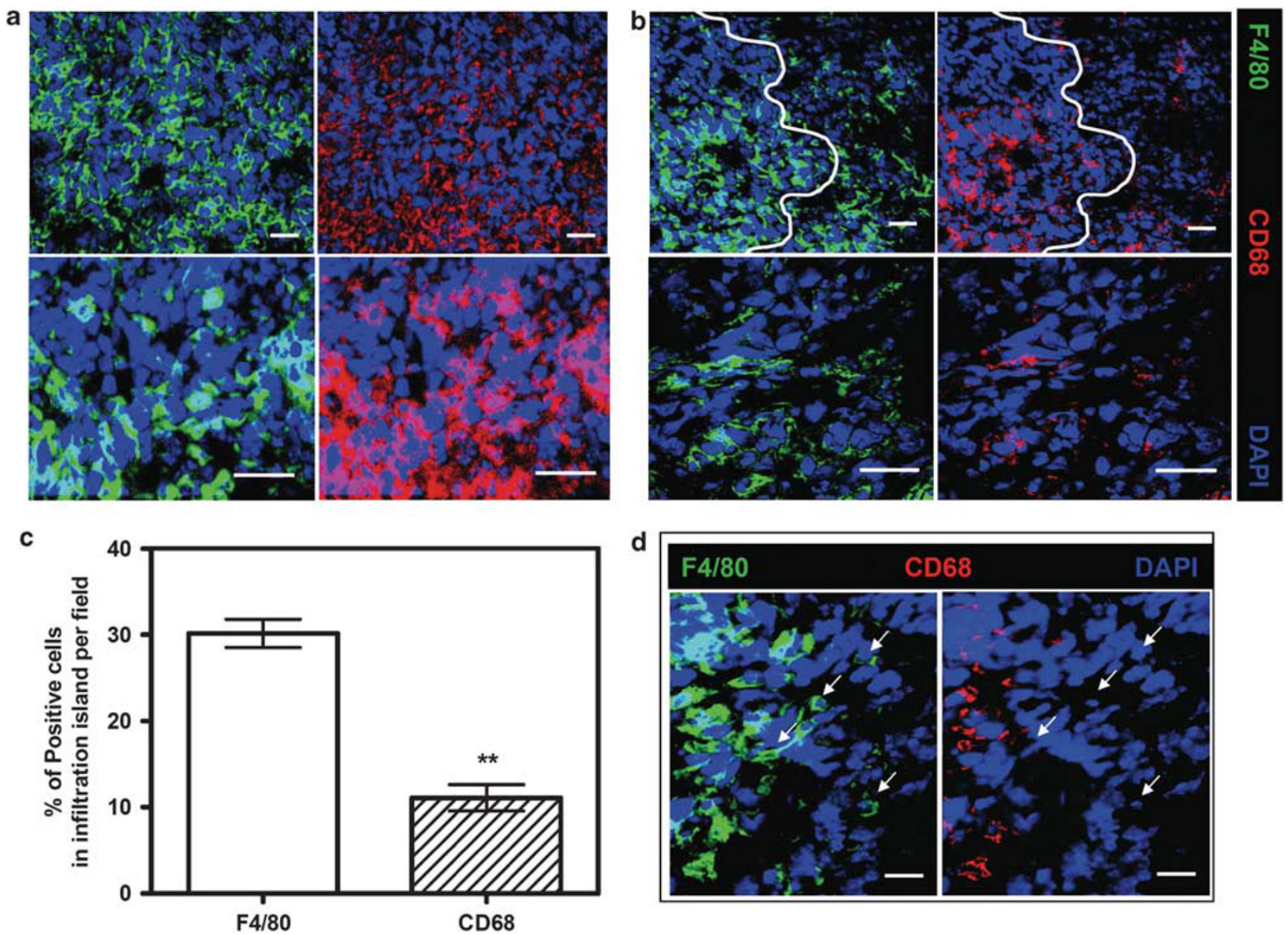

Figure 3 Comparison of the expression of CD68 and F4/80 on tumor cores vs tumor margins of ALTS1C1 brain tumors using confocal imaging of double IHC staining for F4/80 (green), CD68 (red), and nuclei by DAPI (blue) on ALTS1C1 brain tumor core (a) and tumor margin (b). Scale bar $=50 \mu$ m.

(c) Quantification of CD68- and F4/80-positive cells in tumor infiltrating region ( $n=6-10$ fields per tumor of total three tumors; ${ }^{* *} P<0.01$ ).

(d) Higher magnification of confocal imaging of CD68 and F4/80 distribution on the ALTS1C1 infiltrating tumor region. Scale bar $=20 \mu \mathrm{m}$.

Figure 4d) compared with $6.9 \pm 3.1$ per section in $\mathrm{SDF}^{\mathrm{kd}}$ tumors $(P<0.0001)$ (Figure $4 \mathrm{~d})$.

Preferential localization of TAMs in hypoxic areas in tumors has been reported in various tumor models. ${ }^{31,32}$ In ALTS1C1 tumors (top panel in Figure 5a), these were CD68 + more than F4/80 + TAMs (Figure 5b). Interestingly, in SDF ${ }^{\mathrm{kd}}$ tumors, the correlation of the number of TAMs with hypoxia was disrupted (bottom panel in Figure 5a). There was no preferential localization of CD68 + TAMs in hypoxic areas (Figure $5 \mathrm{c}$ ) and the normally more randomly distributed F4/ $80+$ TAMs became more concentrated in PIMO-negative regions (Figure $5 \mathrm{c}$ ), indicating that SDF-1 might be a key factor in TAM tropism toward hypoxic regions.

\section{The Role of SDF-1 on TAM Accumulation in Hypoxic Regions}

Two possible mechanisms may explain the observed changes in the association of TAMs with hypoxia in SDF ${ }^{\mathrm{kd}}$ tumors. The first is that SDF-1 has a chemotropic effect for TAM tropism toward hypoxia. This is partially supported by IHC staining of ALTS1C1 tumors, showing the SDF-1 signal co-localized with PIMO (Figure 6a) and HIF-1 $\alpha$ (Figure 6b) positive regions, although both were not exactly superimposed, most likely due to constitutive production of SDF-1 by ALTS1C1 cells. The PIMO-positive regions also contained a higher signal for the SDF-1 receptor, CXCR4 (Figure 6c), which also co-localized with CD68-positive TAMs (Figure 6d). This further indicates the essential role of the hypoxiaregulated SDF/CXCR4 axis on TAM migration toward hypoxia. The concept of an SDF-1 concentration gradient being the driving force for TAM tropism toward hypoxia was further supported by a migration assay. Figure 7a shows that $50 \%$ ALTS1C1 conditioned medium (CM), but not SDF ${ }^{\mathrm{kd}}$ $\mathrm{CM}$, had a similar effect as $10 \mathrm{ng} / \mathrm{ml}$ of recombinant SDF- 1 on chemotaxis of Raw264.7 cells. This was further enhanced under hypoxic conditions. The second hypothesis is that SDF- 1 is a survival factor for TAMs in hypoxia. To test this possibility, cell death assays were performed. Figure $7 \mathrm{~b}$ shows that $60-80 \%$ of Raw 264.7 cells grown in control medium or in $50 \%$ of $\mathrm{SDF}^{\mathrm{kd}} \mathrm{CM}$ died (Annexin $\mathrm{V}+/ 7-\mathrm{AAD}+$ ) after $72 \mathrm{~h}$ in 
a
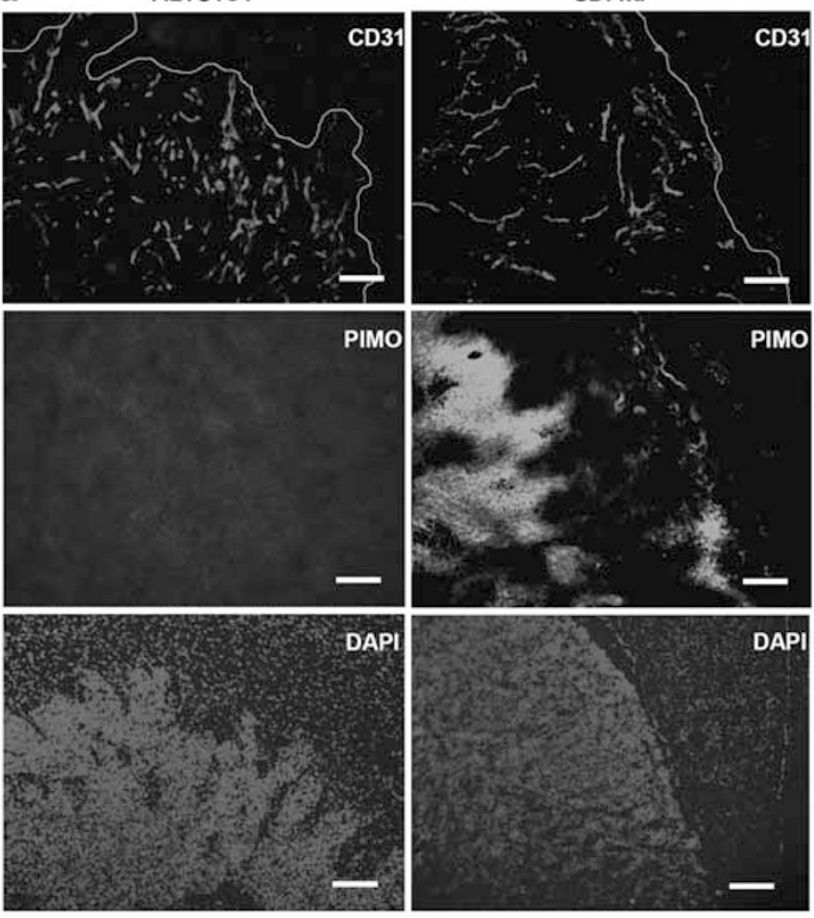

b

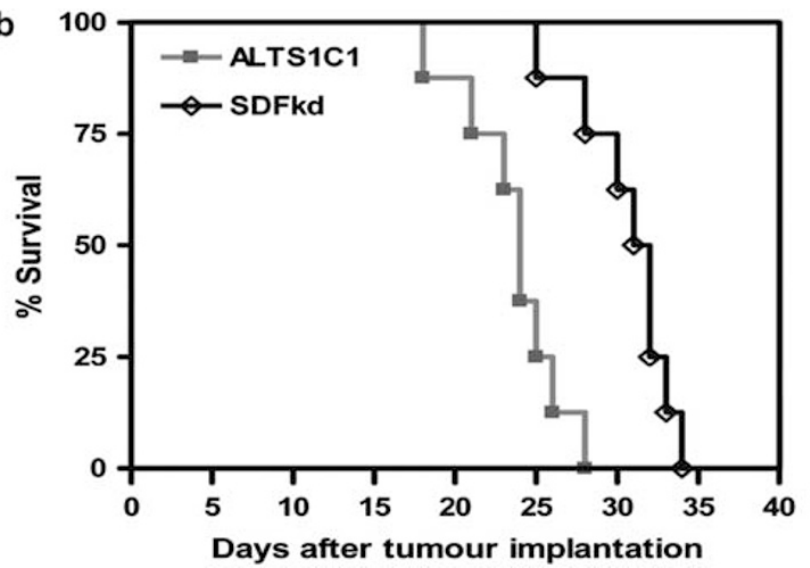

C
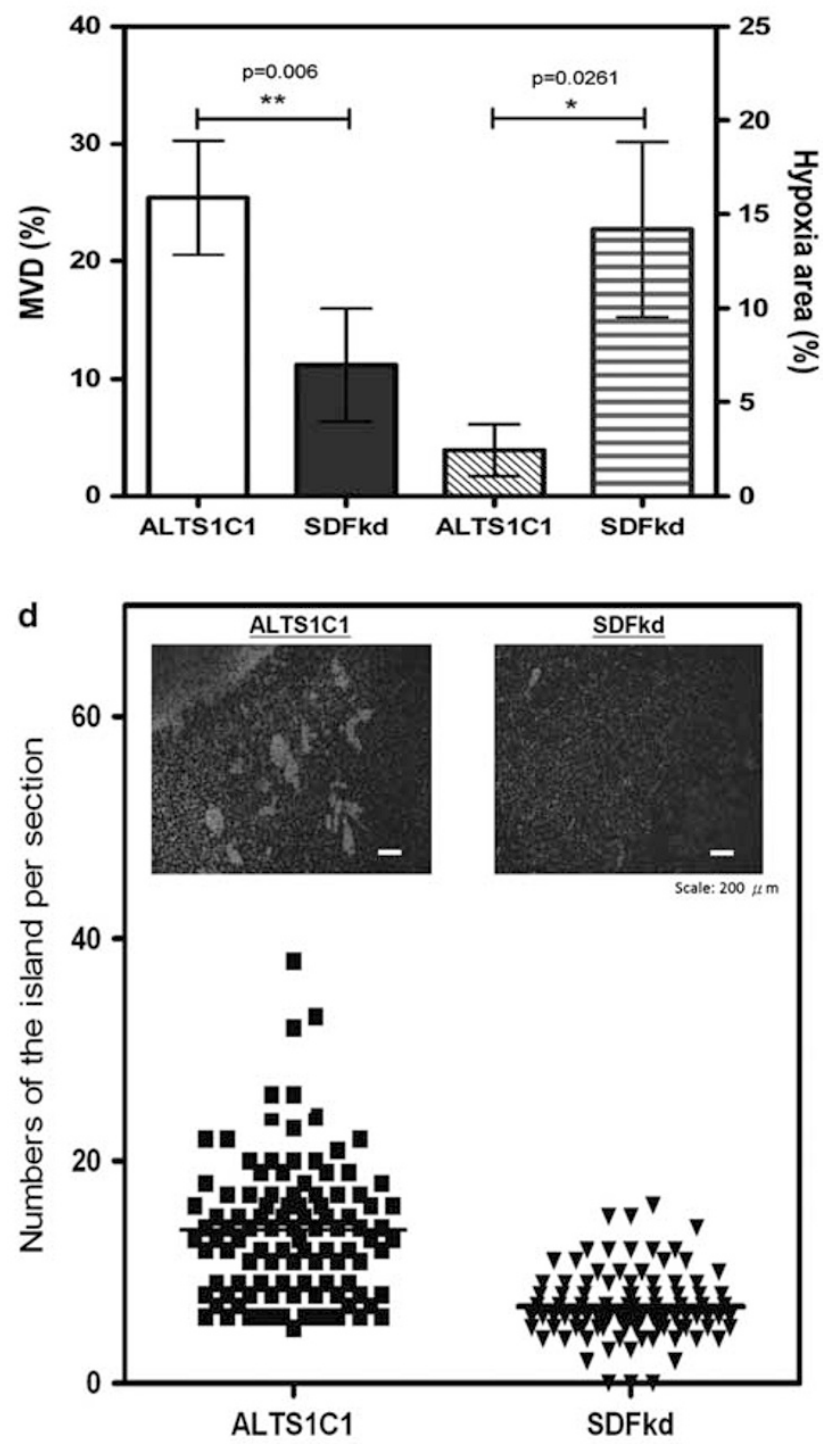

Figure 4 Suppression of SDF-1 expression decreases MVD, increases hypoxia, and inhibits tumor invasion. (a) IHC staining of ALTS1C1 and SDF ${ }^{\mathrm{kd}}$ tumors grown in the brain of syngeneic mice. Tumor sections were stained for CD31 (red) and PIMO (green). Nucleus staining with DAPI is shown in blue. Scale bar $=200 \mu \mathrm{m}$. (b) Kaplan-Meier survival curves of ALTS1C1 and SDF ${ }^{\mathrm{kd}}$ glioma-bearing mice $(n=8)$. (c) Quantification of CD31 + MVD and PIMO + hypoxic areas in control ALTS1C1 or SDF ${ }^{k d}$ brain tumors. Symbols and error bars are mean \pm s.d. for $n=3$ animals per group. ${ }^{\star} P<0.05,{ }^{* * P}<0.01$. (d) Scatter plot of invasion islands between ALTS1C1 and SDF ${ }^{\mathrm{kd}}$ brain tumors. The invasive pattern was assessed on whole brain serial sections by DAPI stain. The thickness of each section was $10 \mu \mathrm{m}$ and every 10th section was used to count the tumor invading islands. An island was scored as positive when the value of ((island length + island width) $/ 2 \leqslant 200 \mu \mathrm{m}$ ) each island was not connected to the main tumor edge. The plot represents the average island number of each section from three brains on each group observed under $\times 100$ power microscope. $P<0.001$.

hypoxia whereas only $\sim 40 \%$ died in ALTS1C1 CM. When combined, these in vitro results indicated that SDF-1 is a critical chemoattractant for TAMs toward hypoxic regions and may also be a survival factor.

\section{DISCUSSION}

In this study, we report on the establishment of a new murine anaplastic astrocytoma cell line, ALTS1C1, through in vitro transformation of astrocytes by SV40 LTA followed by serial in vivo subcutaneous and intracerebral propagation. ALTS1C1 became a stable cell line, like GL261, ${ }^{33-35}$ that can grow intracerebrally in syngeneic C57BL/6J mice and consistently recapture many of the features of malignant brain tumors, such as irregular borders with clearly invading tracts of tumor cells infiltrating into adjacent normal brain regions leading to neurological symptoms. These two tumor models 


\section{a ALTS1C1_Con}

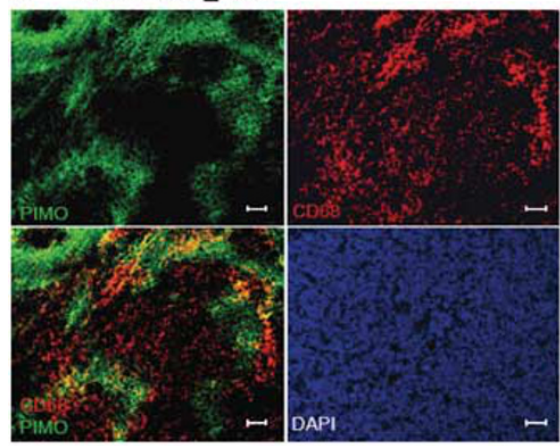

ALTS1C1_SDFkd
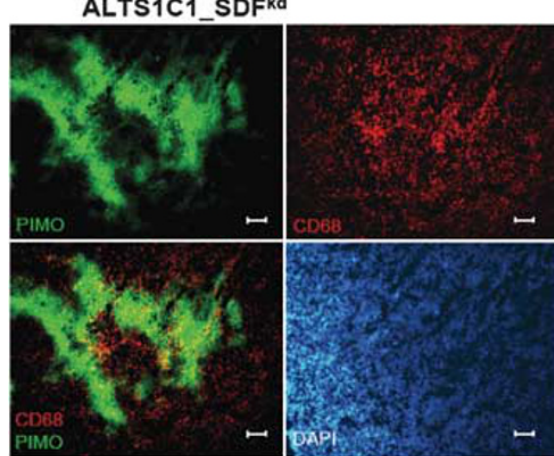

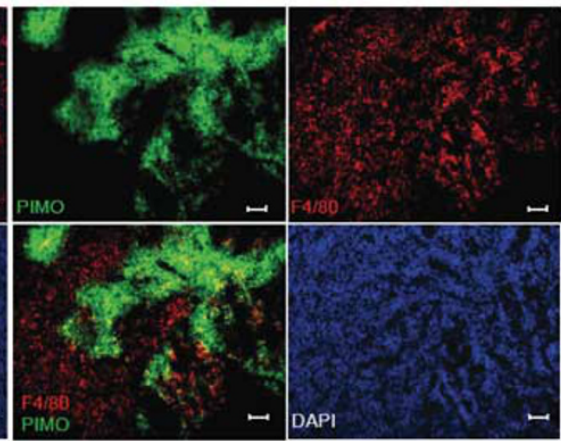

b
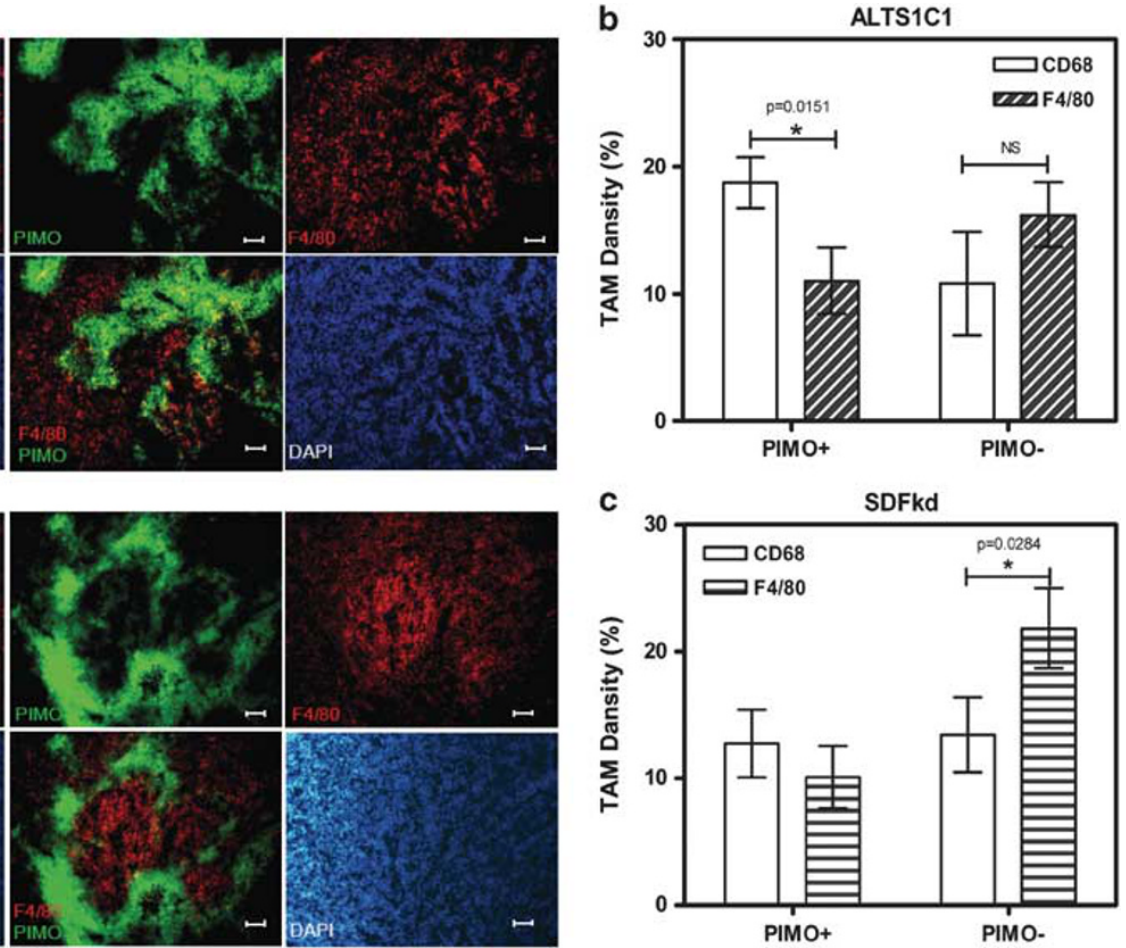

c

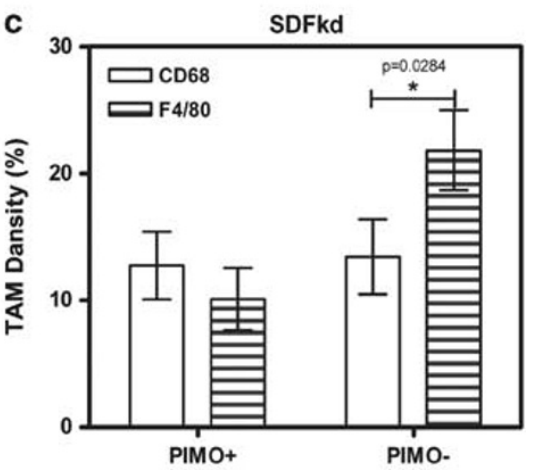

Figure 5 Suppression of SDF-1 expression disrupts the association of TAMs with hypoxia. (a) Double IHC staining for CD68 (red) and PIMO (green) or F4/80 (red) and PIMO (green) in ALTS1C1 or SDF ${ }^{\mathrm{kd}}$ brain tumor sections. Co-localization of TAMs with PIMO is shown in merged images. Nuclear staining by DAPI is shown in blue. Scale bar $=100 \mu \mathrm{m}$. (b) Quantification of the CD68 + or F4/80 + TAM density in PIMO + hypoxic or PIMOnon-hypoxic areas of ALTS1C1 or (c) SDF ${ }^{\mathrm{kd}}$ tumors. Symbols and error bars are mean \pm s.d. for six fields of three tumors per group, ${ }^{\star} P<0.05$.

are associated with different carcinogenic changes. The ALTS1C1 malignant astrocytoma was initiated through inactivation of the p53 pathway by LTA while the GL261 was chemically induced and has constitutive activation of PI3K signaling pathway. ${ }^{36}$ These differences will cause variation in the factors released by the cells and responses to therapy. For example, the expression of relatively high levels of SDF-1 by ALTS1C1 cells could be a direct consequence p53 inactivation. ${ }^{37,38}$ The fact that the highest levels of SDF-1 were found in the infiltrating tumor front and invasion islands that were associated with high MVD and TAMs confers on this model suitability for preclinical testing of therapeutic strategies and for study of the roles of the microenvironment in glioma infiltration.

In addition to the well-known function of SDF-1 in mobilization of CD34 + hematopoietic progenitor cells, ${ }^{39,40}$ SDF-1 has recently been shown to be an important HIF-1 downstream factor for the recruitment of bone marrowderived cells into GBM. Furthermore, interruption of the SDF-1/CXCR4 interaction by AMD3100 blocked the backup vasculogenesis pathway that contributed to tumor growth, augmenting the anti-angiogenic effects of RT and preventing recurrence of GBM tumors. ${ }^{41}$ Hypoxia may, however, not be the only factor driving SDF-1 production, as it is strongly expressed in tumor infiltrating islands that have high MVD and TAM content, but are rarely hypoxic. The alternative hypothesis is that SDF-1 production by tumor cells acts as an autocrine factor to drive tumor invasiveness is suggested by the loss of infiltrating tracts in SDF ${ }^{\mathrm{kd}}$. Hypoxia does not seem to be a factor in the high expression of SDF-1 by tumor cells adjacent to CXCR4-positive neovessels that has been found in GBM specimens ${ }^{42}$ where it seems to regulate growth factorinduced angiogenesis. ${ }^{43,44}$ Hypoxia may, however, serve as an additional factor driving SDF-1 production by TAMs and endothelial cells in $\mathrm{SDF}^{\mathrm{kd}}$ tumors (Supplementary Figure S5d), although this seems inadequate for tumor invasion as these tumors have less infiltrating tracts. This role for SDF-1 in invasion is seen in several in vitro tumor models ${ }^{45,46}$ and a critical amount of SDF-1 may be required or SDF-1 its production by tumor cells to achieve the invasive effect. Whether SDF-1 can act as an internal autocrine (intracrine) invasive factor and what the signaling pathways are activated by SDF-1 to promote glioma invasion in vivo are currently under investigation.

SDF-1 also has a key role in TAM tropism toward hypoxia, which is in agreement with the several reports showing that the binding of HIF-induced SDF-1 with its receptor, CXCR4, on the BMDCs is crucial for the recruitment and retention of BMDC in hypoxia. ${ }^{29,47-50}$ CXCR4 expressed by CD68-positive TAMs in ALTS1C1 tumors correlated with the intensity of PIMO staining (Figure 6d). Our in vitro experiments demonstrated that ALTS1C1 CM, but not $\mathrm{SDF}^{\mathrm{kd}} \mathrm{CM}$, was 
a
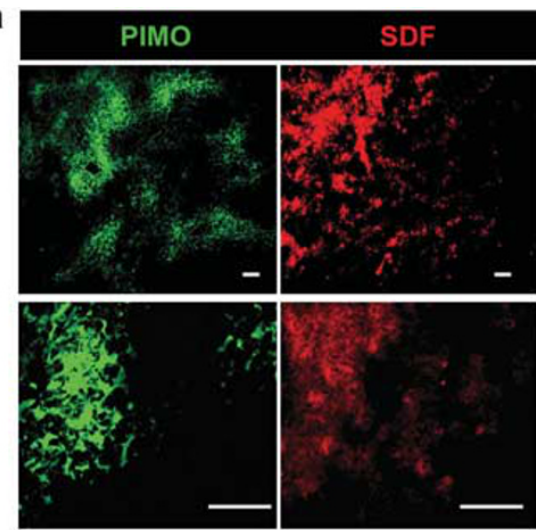

C

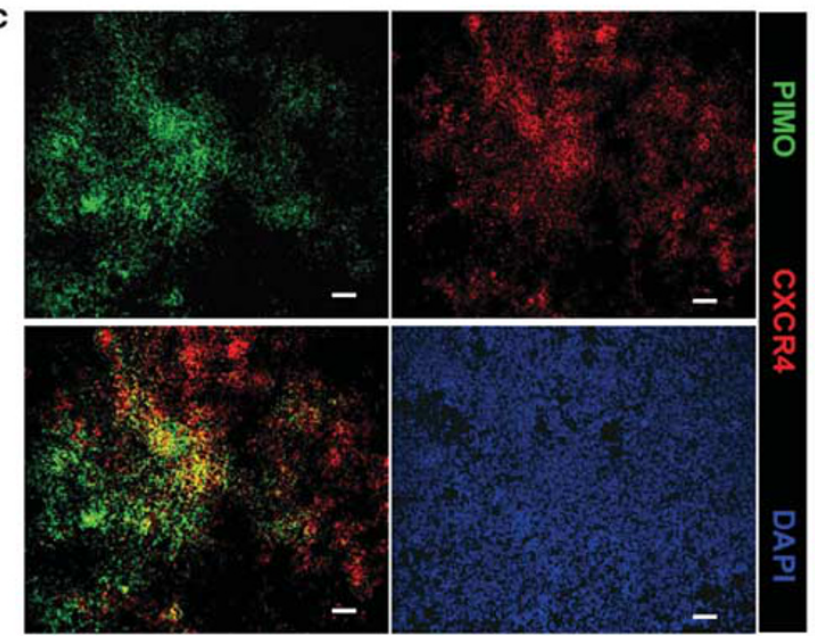

b
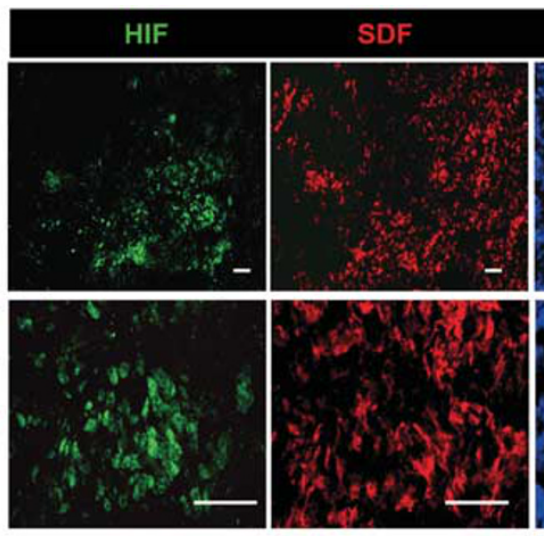

d
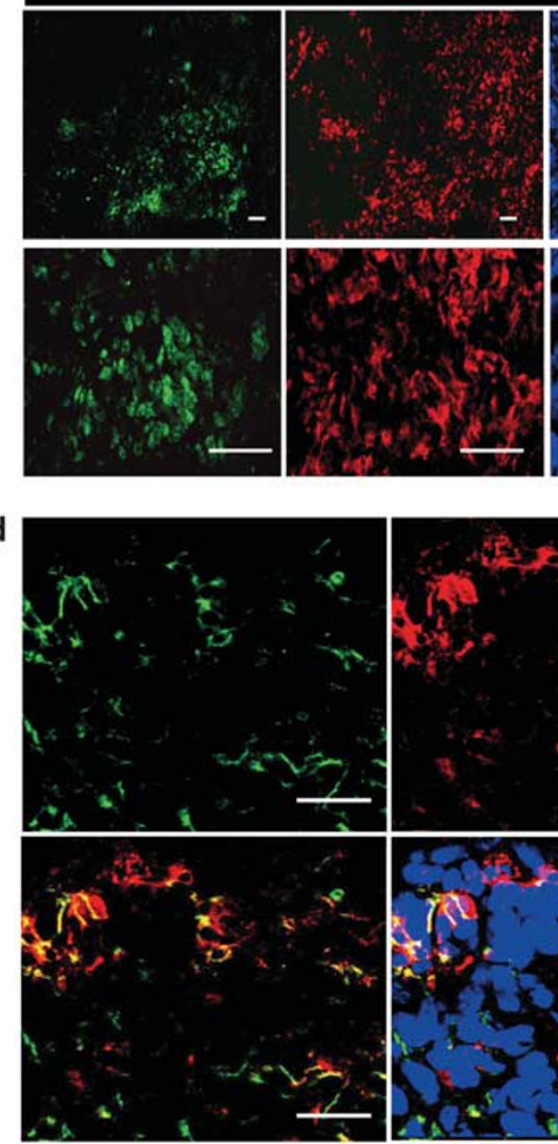

SDF

DAPI
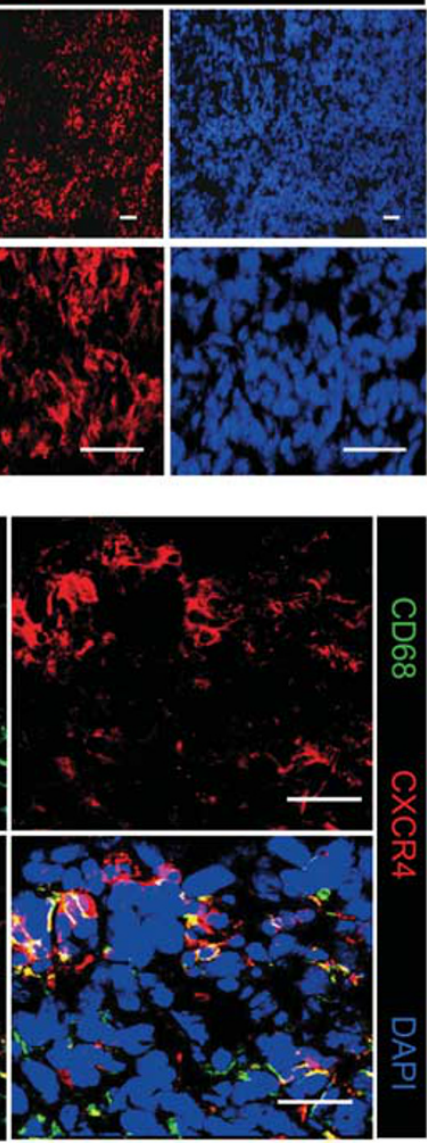

Figure 6 Double IHC staining for (a) SDF-1 (red) and PIMO (green), (b) SDF-1 (red) and HIF-1 $\alpha$ (green), (c) CXCR4 (red) and PIMO (green), or (d) CXCR4 (red) and CD68 (green) in ALTS1C1 brain tumors. Nucleus staining with DAPI is shown in blue. Scale bar $=100 \mu \mathrm{m}$.

a

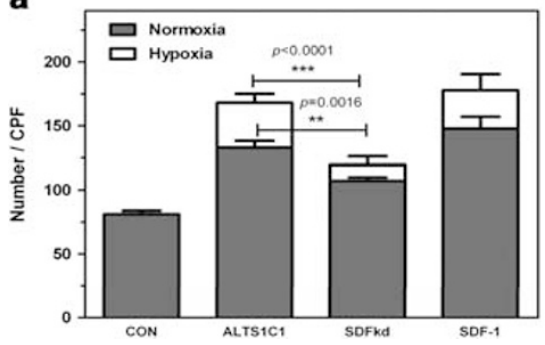

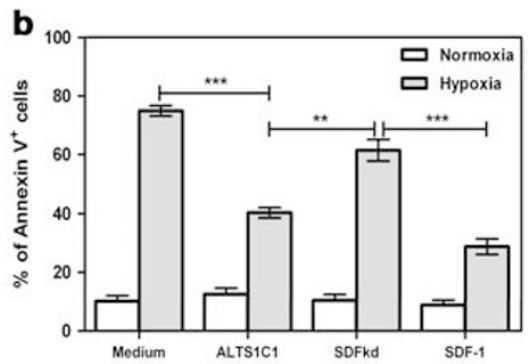

Figure 7 SDF-1 is a chemotactic and survival factor for TAMs in hypoxia. (a) Migration assay for Raw264.7 cells toward medium containing normal culture medium (CON), 50\% of ALTS1C1 CM (ALTS1C1), 50\% of SDF ${ }^{\mathrm{kd}}$ CM (SDFkd), or $10 \mathrm{ng} / \mathrm{ml}$ of recombinant SDF-1 (SDF-1) in normoxia or hypoxia chamber. Cells were allowed to migrate for $6 \mathrm{~h}$ at $37{ }^{\circ} \mathrm{C}$ before staining and quantitation. Data represent average \pm s.d. for $8-10$ randomly selected fields of each well ( $n=3$ wells each group). Data are representative of three independent experiments $\left({ }^{* *} P<0.01,{ }^{* * *} P<0.001\right)$. (b) Percentage of Raw264.7 cells dead after $72 \mathrm{~h}$ in culture containing normal medium (medium), 50\% of ALTS1C1 CM (ALTS1C1), 50\% of SDF ${ }^{\mathrm{kd}}$ CM (SDFkd), or $10 \mathrm{ng} / \mathrm{ml}$ of recombinant SDF-1 (SDF-1) in normoxia or hypoxia chamber. Cells were stained by Annexin V-FITC/7-AAD dyes, and then analyzed by flow cytometry. Percentage of Annexin V +/7-AAD + cells was used to quantify cell death. All cultures were done in triplicate. Symbols and error bars are mean \pm s.d. of three independent experiments.

as effective as $10 \mathrm{ng} / \mathrm{ml}$ of SDF-1 at attracting the monocytic cell line, Raw264.7. Chemoattraction was further enhanced under hypoxia and may be associated with HIF-induced
CXCR4 expression by macrophages. ${ }^{51}$ The finding of more F4/80 + TAMs in PIMO-negative (non-hypoxic) areas of $\mathrm{SDF}^{\mathrm{kd}}$ tumors indicates that SDF-1 may have an additional 
role in protecting TAMs from hypoxia-induced cell death. A recent report shows that SDF- $1 \alpha$-mediated PI3K/AKT and ERK1/1 signaling can prevent hypoxia-induced apoptosis in bone marrow-derived mesenchymal stem cells. ${ }^{52}$ Whether similar mechanisms can occur in this tumor model requires further investigation, although we have found that the monocytic cell line, Raw264.7, in ALTS1C1 CM was more resistant to hypoxic stress than in $\mathrm{SDF}^{\mathrm{kd}} \mathrm{CM}$.

As reported, ${ }^{10,53}$ various subtypes of TAMs have different effects on tumor growth and prognosis. While the M1 phenotype has anti-tumor effects, M2 may promote tumor growth, ${ }^{27}$ immune suppression, ${ }^{54,55}$ or tumor re-growth after RT. ${ }^{56}$ The functional phenotypes of TAMs can change in response to different microenvironments. ${ }^{57,58}$ This has brought caution to defining TAM subtypes. We have not clearly defined the roles of various subtypes of TAMs found in this tumor model, but those in the primary tumor core are clearly different from those in the infiltrating front. Most TAMs in the primary tumor core are CD68 and F4/80 double positive, but are more F4/80-positive than CD68-positive TAMs in the tumor front and infiltration tumor islands. We also noticed a subset of F4/ $80+/$ CD68 - TAMs in infiltration tumor that were rarely found in the primary tumor core, or in published articles. Brain TAMs contain at least two major populations derived from microglia and infiltrating macrophages. Microglia can be stained as $\mathrm{CD} 11 \mathrm{~b}+\mathrm{CD} 45^{\text {low }}$ and infiltrating macrophages as $\mathrm{CD} 11 \mathrm{~b}+\mathrm{CD} 45^{\text {hi }}$ (ref. 59). This approach cannot compare the difference between the primary core and infiltrating tumor but our study does indicate that particular subtypes of TAMs may be more important for glioma invasiveness and that this requires an interaction with SDF-1 signaling pathways.

The differing density of CD68 + vs F4/80 + TAMs in PIMO-positive and -negative regions supports our hypothesis that different subtypes of TAMs may have different roles. In PIMO-negative regions of ALTS1C1 tumors, the density of F4/80 + and CD68 + TAMs were the same, but the former was significantly increased in $\mathrm{SDF}^{\mathrm{kd}}$ tumors. Many reports have strongly suggested that the TAMs in hypoxic regions most likely belong to the M2 phenotype. ${ }^{31,32,60,61}$ Whether this implies that F4/80-positive TAMs have a stronger association with tumor invasion than CD68-positive TAMs is an interesting question that we are still unclear on at present.

In summary, we have characterized the tumor microenvironment of a newly established preclinical glioma model, ALTS1C1, derived from astrocytes by SV40-LTA. Using this model, we demonstrated that tumor-secreted SDF-1 is a critical driving force for glioma invasiveness and a chemoattracting or surviving factor for TAM tropism toward hypoxia. This can be a good brain tumor model to use for the design for new treatment options for targeting as well as for better understanding the microenvironment for infiltrating glioma.

Supplementary Information accompanies the paper on the Laboratory Investigation website (http://www.laboratoryinvestigation.org)

\section{ACKNOWLEDGEMENTS}

This work was supported by NSC 99-2627-M-007-008, NHRI-EX100-9827BI, and 99N82427E1 from the National Science Council, National Health Research Institute, and National Tsing Hua University, respectively, Taiwan, to Chi-Shiun Chiang. Shu-Chi Wang was supported by NSC-096-2917-I-007-101 from the National Science Council. We thank Professor William H McBride, UCLA, for helpful discussions and proofreading on this manuscript. We are grateful to the Imaging Center of National Synchrotron Radiation Research Center for allowing us to use the Laser Scanning Confocal Microscopy and Dr Ling, Kun-Ju, Department of Medical Imaging and Radiological Sciences, Chang Gung Memorial Hospital, Taiwan, for helping the PET imaging. Ms Pan, Yi-Hsin, Department of Biomedical Engineering and Environmental Sciences, National Tsing Hua University, for preparing ${ }^{18} \mathrm{FDG}$ probe.

\section{DISCLOSURE/CONFLICT OF INTEREST}

The authors declare no conflict of interest.

1. Stupp R, Mason WP, van den Bent MJ, et al. Radiotherapy plus concomitant and adjuvant temozolomide for glioblastoma. N Engl J Med 2005;352:987-996.

2. Gladson CL, Prayson RA, Liu WM. The pathobiology of glioma tumors. Annu Rev Pathol 2010;5:33-50.

3. Brown JM. The hypoxic cell: a target for selective cancer therapyeighteenth Bruce F. Cain Memorial Award lecture. Cancer Res 1999; 59:5863-5870.

4. Pilkington GJ, Darling JL, Lantos $\mathrm{PL}$, et al. Cell lines (VMDk) derived from a spontaneous murine astrocytoma. Morphological and immunocytochemical characterization. J Neurol Sci 1983;62:115-139.

5. Yamasaki T, Handa H, Yamashita J, et al. Characteristic immunological responses to an experimental mouse brain tumor. Cancer Res 1983; 43:4610-4617.

6. Morris VL, Tieszer C, Mackinnon J, et al. Characterization of coronavirus $\mathrm{JHM}$ variants isolated from Wistar Furth rats with a viral-induced demyelinating disease. Virology 1989;169:127-136.

7. Weiner NE, Pyles RB, Chalk CL, et al. A syngeneic mouse glioma model for study of glioblastoma therapy. J Neuropathol Exp Neurol 1999;58:54-60.

8. Szatmari T, Lumniczky K, Desaknai S, et al. Detailed characterization of the mouse glioma 261 tumor model for experimental glioblastoma therapy. Cancer Sci 2006;97:546-553.

9. Nishie $A$, Ono $M$, Shono $T$, et al. Macrophage infiltration and heme oxygenase-1 expression correlate with angiogenesis in human gliomas. Clin Cancer Res 1999;5:1107-1113.

10. Lewis CE, Pollard JW. Distinct role of macrophages in different tumor microenvironments. Cancer Res 2006;66:605-612.

11. Tabatabai G, Frank B, Mohle R, et al. Irradiation and hypoxia promote homing of haematopoietic progenitor cells towards gliomas by TGFbeta-dependent HIF-1alpha-mediated induction of CXCL12. Brain 2006;129:2426-2435.

12. Esencay M, Newcomb EW, Zagzag D. HGF upregulates CXCR4 expression in gliomas via NF-kappaB: implications for glioma cell migration. J Neurooncol 2010;99:33-40.

13. Balkwill F. Chemokine biology in cancer. Semin Immunol 2003;15: 49-55.

14. Dewan MZ, Ahmed S, Iwasaki Y, et al. Stromal cell-derived factor-1 and CXCR4 receptor interaction in tumor growth and metastasis of breast cancer. Biomed Pharmacother 2006;60:273-276.

15. Luker KE, Luker GD. Functions of CXCL12 and CXCR4 in breast cancer. Cancer Lett 2006;238:30-41.

16. Liang $\mathrm{Z}, \mathrm{Wu} \mathrm{H}, \mathrm{Reddy} \mathrm{S}$, et al. Blockade of invasion and metastasis of breast cancer cells via targeting CXCR4 with an artificial microRNA. Biochem Biophys Res Commun 2007;363:542-546.

17. Orimo A, Gupta PB, Sgroi DC, et al. Stromal fibroblasts present in invasive human breast carcinomas promote tumor growth and angiogenesis through elevated SDF-1/CXCL12 secretion. Cell 2005; 121:335-348.

18. Zheng $H, F u ~ G$, Dai $T$, et al. Migration of endothelial progenitor cells mediated by stromal cell-derived factor-1alpha/CXCR4 via PI3K/Akt/ eNOS signal transduction pathway. J Cardiovasc Pharmacol 2007;50: 274-280. 
19. Chiang CS, McBride WH. Radiation enhances tumor necrosis factor alpha production by murine brain cells. Brain Res 1991;566: 265-269.

20. Ariga $\mathrm{H}$, Sugano $\mathrm{S}$. Initiation of simian virus 40 DNA replication in vitro. J Virol 1983;48:481-491.

21. Newcomb EW, Lukyanov $\mathrm{Y}$, Kawashima $\mathrm{N}$, et al. Radiotherapy enhances antitumor effect of anti-CD137 therapy in a mouse Glioma model. Radiat Res 2010;173:426-432.

22. Mendez O, Zavadil J, Esencay M, et al. Knock down of HIF-1alpha in glioma cells reduces migration in vitro and invasion in vivo and impairs their ability to form tumor spheres. Mol Cancer 2010;9:133.

23. Foster BA, Gingrich JR, Kwon ED, et al. Characterization of prostatic epithelial cell lines derived from transgenic adenocarcinoma of the mouse prostate (TRAMP) model. Cancer Res 1997;57: 3325-3330.

24. Ohgaki $\mathrm{H}$, Kleihues $\mathrm{P}$. Genetic alterations and signaling pathways in the evolution of gliomas. Cancer Sci 2009;100:2235-2241.

25. Ohgaki $\mathrm{H}$, Kleihues $\mathrm{P}$. Genetic pathways to primary and secondary glioblastoma. Am J Pathol 2007;170:1445-1453.

26. Parsons DW, Jones $S$, Zhang $X$, et al. An integrated genomic analysis of human glioblastoma multiforme. Science 2008;321:1807-1812.

27. Bingle L, Brown NJ, Lewis CE. The role of tumour-associated macrophages in tumour progression: implications for new anticancer therapies. J Pathol 2002;196:254-265.

28. Salmaggi A, Gelati M, Pollo B, et al. CXCL12 in malignant glial tumors: a possible role in angiogenesis and cross-talk between endothelial and tumoral cells. J Neurooncol 2004;67:305-317.

29. Aghi M, Cohen KS, Klein RJ, et al. Tumor stromal-derived factor-1 recruits vascular progenitors to mitotic neovasculature, where microenvironment influences their differentiated phenotypes. Cancer Res 2006;66:9054-9064.

30. Komatani H, Sugita $\mathrm{Y}$, Arakawa $\mathrm{F}$, et al. Expression of CXCL12 on pseudopalisading cells and proliferating microvessels in glioblastomas: an accelerated growth factor in glioblastomas. Int J Oncol 2009;34: 665-672.

31. Murdoch C, Giannoudis A, Lewis CE. Mechanisms regulating the recruitment of macrophages into hypoxic areas of tumors and other ischemic tissues. Blood 2004;104:2224-2234.

32. Lewis JS, Lee JA, Underwood JC, et al. Macrophage responses to hypoxia: relevance to disease mechanisms. J Leukoc Biol 1999;66: 889-900.

33. Zagzag D, Miller DC, Chiriboga $L$, et al. Green fluorescent protein immunohistochemistry as a novel experimental tool for the detection of glioma cell invasion in vivo. Brain Pathol 2003;13:34-37.

34. Zagzag D, Zhong H, Scalzitti JM, et al. Expression of hypoxia-inducible factor 1alpha in brain tumors: association with angiogenesis, invasion, and progression. Cancer 2000;88:2606-2618.

35. Zagzag D, Amirnovin R, Greco MA, et al. Vascular apoptosis and involution in gliomas precede neovascularization: a novel concept for glioma growth and angiogenesis. Lab Invest 2000;80:837-849.

36. Newcomb EW, Zagzag D. The Murine GL261 glioma experimental model to assess novel brain tumor treatments. In: Van Meir EG (ed). Cancer Drug Discovery and Development. Humana Press: Atlanta, GA, 2009, pp 227-241.

37. Moskovits N, Kalinkovich A, Bar J, et al. p53 Attenuates cancer cell migration and invasion through repression of SDF-1/CXCL12 expression in stromal fibroblasts. Cancer Res 2006;66:10671-10676.

38. Addadi Y, Moskovits N, Granot D, et al. p53 status in stromal fibroblasts modulates tumor growth in an SDF1-dependent manner. Cancer Res 2010;70:9650-9658.

39. Aiuti A, Webb IJ, Bleul C, et al. The chemokine SDF-1 is a chemoattractant for human CD34+ hematopoietic progenitor cells and provides a new mechanism to explain the mobilization of CD34+ progenitors to peripheral blood. J Exp Med 1997;185:111-120.
40. Pusic I, DiPersio JF. Update on clinical experience with AMD3100, an SDF-1/CXCL12-CXCR4 inhibitor, in mobilization of hematopoietic stem and progenitor cells. Curr Opin Hematol 2010;17:319-326.

41. Kioi M, Vogel H, Schultz G, et al. Inhibition of vasculogenesis, but not angiogenesis, prevents the recurrence of glioblastoma after irradiation in mice. J Clin Invest 2010;120:694-705.

42. Rempel SA, Dudas S, Ge S, et al. Identification and localization of the cytokine SDF1 and its receptor, CXC chemokine receptor 4, to regions of necrosis and angiogenesis in human glioblastoma. Clin Cancer Res 2000;6:102-111.

43. Salvucci O, Yao L, Villalba $\mathrm{S}$, et al. Regulation of endothelial cell branching morphogenesis by endogenous chemokine stromal-derived factor-1. Blood 2002;99:2703-2711.

44. Salcedo R, Oppenheim JJ. Role of chemokines in angiogenesis: CXCL12/SDF-1 and CXCR4 interaction, a key regulator of endothelial cell responses. Microcirculation 2003;10:359-370.

45. Kenig S, Alonso MB, Mueller MM, et al. Glioblastoma and endothelial cells cross-talk, mediated by SDF-1, enhances tumour invasion and endothelial proliferation by increasing expression of cathepsins B, S, and MMP-9. Cancer Lett 2010;289:53-61.

46. Rehman AO, Wang CY. CXCL12/SDF-1 alpha activates NF-kappaB and promotes oral cancer invasion through the Carma3/Bcl10/Malt1 complex. Int J Oral Sci 2009;1:105-118.

47. Ceradini DJ, Kulkarni AR, Callaghan MJ, et al. Progenitor cell trafficking is regulated by hypoxic gradients through HIF-1 induction of SDF-1. Nat Med 2004;10:858-864.

48. Wang $\mathrm{Y}$, Haider $\mathrm{H}$, Ahmad $\mathrm{N}$, et al. Evidence for ischemia induced hostderived bone marrow cell mobilization into cardiac allografts. J Mol Cell Cardiol 2006;41:478-487.

49. Jin DK, Shido K, Kopp HG, et al. Cytokine-mediated deployment of SDF-1 induces revascularization through recruitment of CXCR4+ hemangiocytes. Nat Med 2006;12:557-567.

50. Grunewald M, Avraham I, Dor Y, et al. VEGF-induced adult neovascularization: recruitment, retention, and role of accessory cells. Cell 2006; 124:175-189.

51. Fang HY, Hughes R, Murdoch C, et al. Hypoxia-inducible factors 1 and 2 are important transcriptional effectors in primary macrophages experiencing hypoxia. Blood 2009;114:844-859.

52. Yin $Q$, Jin $P$, Liu $X$, et al. SDF-1alpha inhibits hypoxia and serum deprivation-induced apoptosis in mesenchymal stem cells through PI3K/Akt and ERK1/2 signaling pathways. Mol Biol Rep 2011;38:9-16.

53. Qian BZ, Pollard JW. Macrophage diversity enhances tumor progression and metastasis. Cell 2010;141:39-51.

54. Mantovani A, Ming WJ, Balotta $C$, et al. Origin and regulatin of tumorassociated macrophages: the role of tumor-derived chemotactic factor. Biochim Biophys Acta 1986;865:59-67.

55. Pollard JW. Tumour-educated macrophages promote tumour progression and metastasis. Nat Rev Cancer 2004;4:71-78.

56. Tsai CS, Chen FH, Wang CC, et al. Macrophages from irradiated tumors express higher levels of iNOS, arginase-I and COX-2, and promote tumor growth. Int J Radiat Oncol Biol Phys 2007;68:499-507.

57. Chiang $\mathrm{CS}$, Chen $\mathrm{FH}$, Hong $\mathrm{JH}$, et al. Functional phenotype of macrophages depends on assay procedures. Int Immunol 2008;20: 215-222.

58. Stout RD, Jiang C, Matta B, et al. Macrophages sequentially change their functional phenotype in response to changes in microenvironmental influences. J Immunol 2005;175:342-349.

59. Watters JJ, Schartner JM, Badie B. Microglia function in brain tumors. J Neurosci Res 2005;81:447-455.

60. Lewis $C E$, Leek $R$, Harris $A$, et al. Cytokine regulation of angiogenesis in breast cancer: the role of tumor-associated macrophages. J Leukoc Biol 1995;57:747-751.

61. Murdoch $C$, Muthana $M$, Lewis CE. Hypoxia regulates macrophage functions in inflammation. J Immunol 2005;175:6257-6263. 